\title{
Parent and Provider Perspectives on Factors Influencing Treatment-Seeking and Recovery After Hospital Discharge Among Undernourished Children Aged 2-23 Months in Bangladesh
}

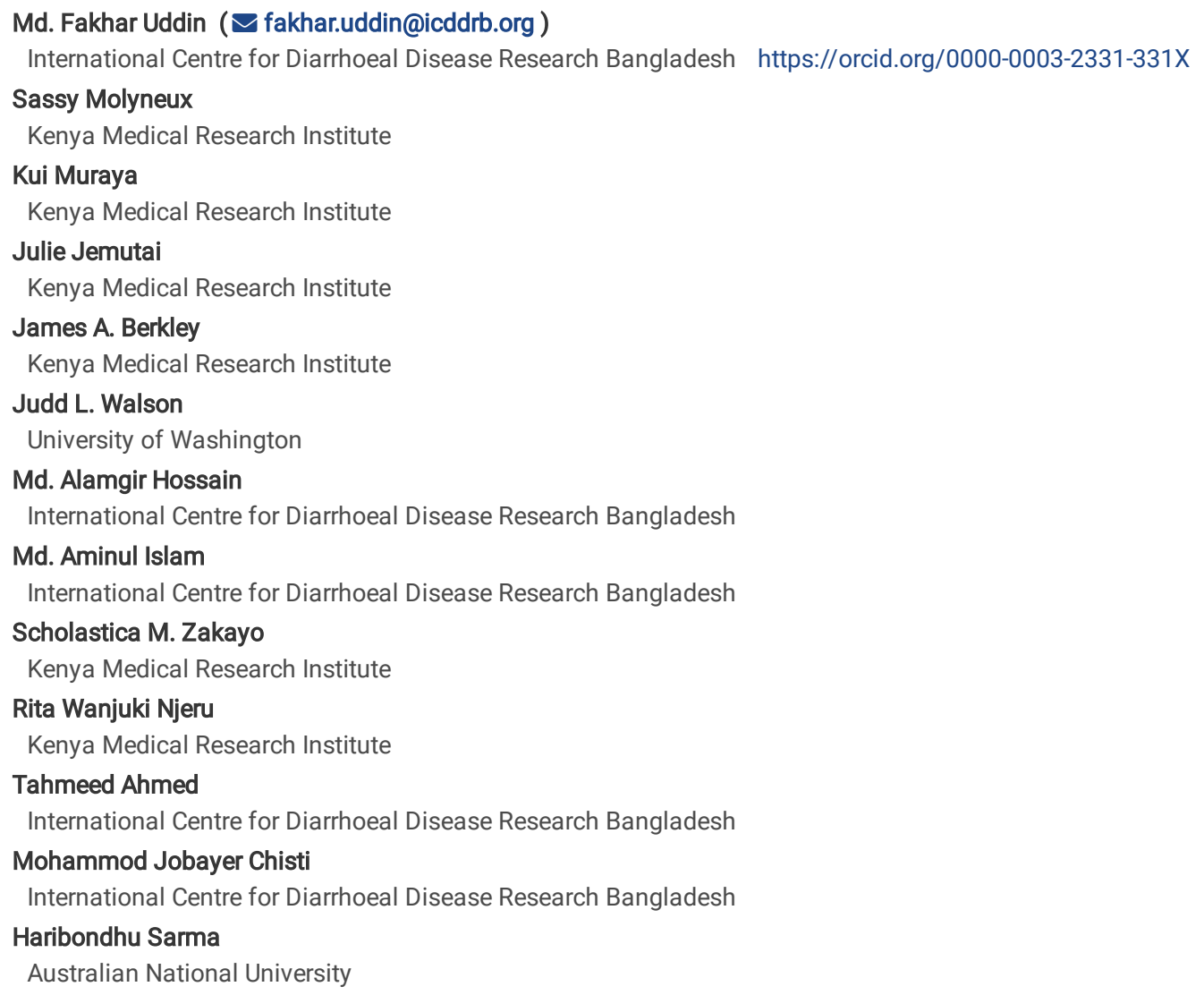




\section{Abstract}

Background: Post-hospital discharge mortality is high among undernourished children in many low and middle-income countries; often exceeding in-patient mortality rates. Although a number of studies have highlighted a range of potential socio-cultural, economic and health system factors influencing paediatric post-discharge treatment-seeking and recovery, including in Bangladesh, few studies have explored parent and provider perspectives.

Methods: As part of a large, multi-country prospective cohort study - the Childhood Acute Illness and Nutrition (CHAIN) Network - we conducted a qualitative study to understand the post-discharge treatment-seeking and recovery experiences of families of undernourished children aged 2-23 months admitted in two icddr,b (International Centre for Diarrhoeal Disease Research, Bangladesh) hospitals. To gather parent perspectives, we gathered in-depth qualitative data from family members of 17 purposively selected undernourished children from a rural and urban hospital. These data were supplemented by observations in hospitals and homes and from health worker interviews. We interviewed family members on discharge and again in their homes after discharge over several visits.

Results: 13 of the 17 purposively selected children were reported by family members to have fully recovered by the time we completed our interviews; four had died. Important perceived drivers of treatment-seeking and recovery included advice provided while in hospital, media campaigns on hygiene practice, positive social and financial support from family members, relatives and neighbours, and the availability of free treatment. Key challenges included low household incomes, mothers having to juggle multiple responsibilities in addition to caring for the child, lack of support - and in some cases violence - from the child's father, and family members' preference for relatively accessible drug shops, physicians or healers over (re)admission to hospital. For most families, a range of challenges interplayed to contribute to early discharge from hospital against medical advice and to non-adherence to follow-up advice. Providers were primarily concerned about an inappropriately high use of antibiotics among families.

Conclusion: Development of interventions that address the range of vulnerabilities that many families face is essential to support post-discharge adherence to medical advice and ensure recovery. These data suggest that potential interventions could include strengthening information giving during hospitalization on what post-discharge care is needed and why, reducing direct and indirect costs associated with hospital visits, engaging fathers and other 'significant others' in post-discharge advice, and building mobile phone-based support for follow-up care.

\section{Background}

Post-hospital discharge mortality is high among children in many low and middle-income countries (LMICs) [1, 2, 3, 4], often exceeding in-hospital mortality rates [5, 6]. A recent systematic review reported pediatric post-discharge mortality rates in resource-poor countries of $1 \%-18 \%$ [5]. Almost half of all deaths occur within 30 days following discharge [2, 4], with children with Severe Acute Malnutrition (SAM) and Moderate Acute Malnutrition (MAM) [7] particularly vulnerable to co-morbidity and mortality $[1,3,4,5,6]$. Two-thirds of pediatric post-discharge death occurs outside the health system, usually in homes [5, 6].

Few studies have examined in-depth post-discharge treatment-seeking and recovery for undernourished children in LMICs from the perspective of children's family members and health providers. The available literature suggests that treatment-seeking and recovery post-discharge will depend not only on the child's physical health at discharge, but also on wider influences across the entire treatment-seeking pathway that shape when, where, and in what condition children are first admitted in hospital, the hospitalization experience itself, and post-hospital discharge actions $[2,4,5,6,8,9]$. Influences can be grouped across three inter-related domains: socio-cultural and environmental; economic; and health system or service influences [10]. Important potential socio-cultural and environmental influences on the treatment-seeking pathway include: levels of education of family members; nature of and adherence to local traditions and beliefs; mothers' decision-making power and access to resources; quality of the household environment including the condition of living areas; and ease of physical accessibility to homes and facilities [2, 8, 9]. Regarding economic factors, important potential influences include: household access to funds to pay for recommended nutritional food for all family members; cost of transport and treatment, including admission and medicine costs; and loss of income associated with caring for children and hospital visits $[2,5,6,11]$. Potential factors at the health system level include hospital discharging practices, availability of essential drugs in the hospital, quality of post-discharge follow-up, access to emergency transportation facilitating children's return to hospital, and caregivers' health care facility experiences $[2,8,11]$.

Factors influencing treatment-seeking and recovery post-discharge are likely to differ between rural and urban settings given their contrasting socio-cultural, environmental, economic, and health system contexts $[12,13,14,15]$. These factors can interact to make children more vulnerable to poor outcomes, such as increased exposure to illness, delayed access to biomedical care, and early discharge from hospital against medical advice [2, 4, 8]. However, household strategies to cope with challenges across these domains, as reflected in treatment-seeking patterns and related decision-making, also highlight household and community resources and individuals' agency (or ability to make choices and to act), even in very difficult situations [16].

In this paper we present parent and health provider perspectives on treatment-seeking and recovery post-hospital discharge for undernourished children admitted in two hospitals in Bangladesh. In Bangladesh, as in other LMICs, post-hospital discharge mortality is high among children. There are no data from public hospitals, but quantitative studies conducted in icddr,b hospitals have documented post-discharge mortality for children aged under five years at $4.2 \%$ and $8.7 \%$ for rural and urban areas respectively $[4,17]$, with $70 \%$ of deaths (rural) and $59 \%$ of deaths (urban) occurring within 3 months and 30 days postdischarge respectively $[4,17]$. Both Severe Acute Malnutrition (SAM) and Moderate Acute Malnutrition (MAM) were associated with higher mortality, and $80 \%$, $16 \%$ and $4 \%$ of deaths occurred outside the health system at home, at other local hospitals and on the way to hospital, respectively [4]. Risk factors for postdischarge death included poor water, sanitation and hygiene practices, maternal education levels and breast-feeding practices $[4,9,17,18]$. Among children with SAM, post-discharge was associated with children leaving the hospital against medical advice due to pressure from family members, non-use by parents of an emergency mobile contact for hospital physicians, and care-seeking from traditional healers [4]. While these quantitative studies have highlighted the need for early detection of a medical problem and continued access to health-care facilities post-discharge, they were not designed to explore parent and provider perspectives of factors influencing post-discharge treatment-seeking and recovery. A greater understanding of factors influencing treatment-seeking

Page 2/15 
and outcomes from the perspective of parents and frontline health providers requires a qualitative approach. Emerging insights can complement quantitative data in identifying locally appropriate interventions with potential to improve children's outcomes.

This phenomenological qualitative study was nested within the Bangladesh site of a large prospective cohort study - "The Childhood Acute Illness and Nutrition (CHAIN) Network": Building the evidence base for care of acutely ill, undernourished children in limited-resource settings" between March 2017 to December $2018[19,20]$. The parent study (CHAIN) is a large multi-country observational cohort study conducted in Bangladesh, Pakistan, Kenya, Uganda, Malawi and Bukina Faso, to better understand risk factors and identify potentially modifiable mechanisms to target in interventions to reduce post-discharge mortality of children [19].

\section{Study Setting And Methods}

\section{The Bangladesh health system context}

Bangladesh is one of the world's fastest-growing economies and one of the fastest-growing lower middle-income countries [21]. However, according to the World Bank, as of $2016,14.8 \%$ population of the country lived below the international poverty line on less than $\$ 1.90$ per day [22]. Bangladesh has a highly pluralistic set of health providers across the country, including formal and informal, traditional and modern, and private and public [23]. Within the public sector, the Ministry of Health and Family Welfare operates a dual system of health and family planning service delivery through medical college hospitals, specialized hospitals, district hospitals, Upazila (sub-district) health complexes (with 51 beds), union health, and family welfare centers and community clinics (CCs) [23]. In rural areas, Health Assistants and Family Welfare Assistants assist community health care providers (CHCP) to run CCs, supported by Community Health Workers (CHWs) linked to non-government organizations (NGOs). In urban areas, the 'Dhaka North City Corporation' and 'Dhaka South City Corporation' (under the Ministry of Local Government) are responsible for providing primary health care services including for the urban poor. Services at this level are offered through a contracted-out mechanism in which NGOs periodically bid to provide low-cost services [24]. In addition, in Dhaka (urban) and Matlab (a rural sub-district), the non-governmental hospitals of icddr,b provide treatment, specializing in diarrhoeal disease [25,26].

\section{Study sites}

The two CHAIN study hospitals in Bangladesh were the icddr,b hospitals in Dhaka (urban) and Matlab (rural)[19]. The Dhaka hospital is located in the capital city and the Matlab hospital about $55 \mathrm{~km}$ southeast of Dhaka, in a sub-district of Chandpur District. These hospitals provide a full range of free treatment and services for patients admitted with diarrheal disease [27-28]. Each year over 100,000 diarrheal patients are admitted in Dhaka hospital and between 20,000 and 25000 in Matlab hospital [27-25,23-24]. Diarrhea is managed according to the hospital's management protocol, with specific guidelines for the management of SAM $[25,29]$. Although they specialize in diarrhoeal treatment, over the years, care has expanded to include respiratory illnesses for children and - in the rural hospital - integrated maternal and child health for the population within the HDSS (Health and Demographic Surveillance System). The Dhaka hospital has an intensive care unit (ICU) and a nutrition rehabilitation unit (NRU), with the care given saving an estimated 40,000 lives per year [30]. In Matlab hospital, children with SAM are discharged from the hospital immediately after recovery from their primary illness, or with significant improvement, as there is no NRU available. Critical patients are referred to the Dhaka Hospital or elsewhere as needed.

Most patients admitted to the two icddr,b hospitals are from low socio-economic backgrounds. In Dhaka city, many hospital users live in one of the city's 'slums', where $37.4 \%$ of city dwellers live and where environments can be very contaminated [31]. When compared to non-slum urban areas, slum-dwelling children are more malnourished have lower immunisation rates, and have higher rates of measles and other infectious diseases. They also suffer more often from diarrhoeal illness and severe dehydration, and their mothers are more likely to be out earning an income [32]. The majority of the admitted children in Matlab hospital of icddr,b were from the Matlab sub-district, which is entirely rural, lacks major towns or cities (except for the Matlab bazaar), and has limited inter-village trade and commerce. The dominant occupations of its population are subsistence farming and fishing [33].

\section{Recruitment of participants and data collection}

A total of 488 undernourished children aged less than 23 months were included in the icddr,b CHAIN cohort, 269 in the urban site and 219 in the rural. Basic socio-economic status data on each child's household (education of caregivers and household assets) and pre-admission treatment-seeking data were collected. We (MFU, MAH, MAl) purposively selected $17 \mathrm{ill}$ undernourished children [34] from the main CHAIN cohort participants (face to face), ensuring diversity in children by location (8 rural and 9 urban), nutritional status, education of parents and exposure to recent major social disruption such as moving house, death of a parent, and change in the main caregiver. We explained the reasons for the selection of these children, our identity, research objectives and activities to caregivers and family members of children.

Family members of selected children were interviewed face to face (17 caregivers, 7 fathers and 5 grandparents) in their homes several times after discharge over the following months [19], supplemented by observations in hospitals and in homes. We (MFU, MAH, MAI) also conducted individual interviews with 15 icddr,b health workers working (particularly involved in providing treatment to the CHAIN cohort participants) in the hospitals (9 urban and 6 rural) and 18 community health workers (CHWs) working in patients' communities (8 urban and 9 rural) to gather their perspectives. None was present besides the participant and researcher during the interview. We had continued data collection until reach the point of data saturation. The average duration of an interview was 48 min. Participants were not refused to participate or dropped out. Repeat interview was not needed to conduct as the lead author-Principal Investigator of the study (MFU) conducted some interviews and checked the quality of other interviews regularly. Other interviewers were also highly trained and experienced in conducting qualitative interviews. Interview timing and location was organized to fit with respondents' needs, and interviews were audiorecorded. 
Interview tools (Additional file 1) were based on the study conceptual framework (Figure 1), in turn based on the literature summarized in the background and pilot tested. We focused on factors influencing the timing of discharge (whether this was early or as per hospital protocol) as well as post-discharge treatmentseeking behavior and adherence to advice. We conceptualized that a range of economic, health service/system, socio-cultural and environmental influences were likely to be at play and that families' treatment-seeking actions and experiences would be shaped by a range of vulnerabilities and some (albeit constrained) agency at these levels.

[Figure 1 to be placed here]

\section{Data analysis}

Qualitative interviews were transcribed verbatim, and interview and observation notes written up immediately following fieldwork into detailed household stories for each child. Transcriptions in Bengali were entered into NVivo11 for coding data using a coding framework based on our initial and emerging themes of interest, and household stories typed up and translated into English using Microsoft Word. At least two researchers coded each transcript, compared results, and resolve any discrepancies for the trustworthiness of the coding process. We combined a narrative approach and a thematic coding approach in the analysis of household data, drawing on our conceptual framework (Figure 1) and looking for patterns of similarity and difference across rural and urban areas. Here, thematic coding supplemented and enriched the narrative analysis. A similar thematic analysis approach was used for health worker data. Transcripts were not returned to the participants for their comments due to our time constraints.

Quantitative data on caregivers' social and household characteristics were collected in the main cohort study [19]. We carried out descriptive analysis of these data for the 17 children included in the qualitative study. We explored the variables in terms of proportions, means and medians where applicable. All analysis was conducted in R for statistical software and STATA version 15.

\section{Ethical approval}

CHAIN protocols were approved for science and ethics in all participating countries. In Bangladesh, the study was approved by the Research Review Committee and the Ethical Review Committee of icddr,b. Written informed consent was sought from participants for all in-depth interviews, observations and recordings, and - continuing consent for households - was checked in each subsequent household visit.

\section{Results}

Following an overview of participant and household characteristics, and of children's treatment-seeking trajectories and health outcomes, we present the key influences on treatment-seeking and post-discharge recovery from the perspective of children's family members and frontline health providers. Influences are grouped according to our conceptual framework domains (Figure 1).

\section{Participant and household characteristics}

The main characteristics of the 17 children involved in the qualitative work are summarized in Table 1. Of the 9 urban children, 6 were SAM, 3 were MAM, and all had experienced a disruption in the family, including recent migration, separation or income-earning loss among parents, maternal illness or a change of caregiver. Of the 8 rural children involved, 4 each were SAM and MAM, with 6 having experienced a family disruption. Across both sites, children were admitted into the hospital and enrolled into the main CHAIN cohort aged 4 to 16 months, with all reported by parents as having been sick on and off since birth. Given that icddr,b hospitals treat children with diarrhea, all children had diarrhea on admission, usually with other symptoms including vomiting ( $n=10)$, fever $(n=7)$ and pneumonia or severe respiratory distress ( $n=5$, all urban). In terms of broad representation of selected participants with wider cohorts in the two sites, we note that our selected children are broadly similar in education level of main caregiver (most are primary school educated or below), in having no reported income, having low levels of food security and in asset scores.

Table 1 Participant and households characteristics 


\begin{tabular}{|c|c|c|c|c|c|c|c|c|c|c|c|c|}
\hline \multirow[t]{2}{*}{ ID } & \multicolumn{6}{|c|}{ Children characteristics } & \multicolumn{5}{|c|}{ Mothers characteristics } & \multirow{2}{*}{$\begin{array}{l}\text { House } \\
\begin{array}{l}\text { Family } \\
\text { structi }\end{array}\end{array}$} \\
\hline & $\begin{array}{l}\text { Nutritional } \\
\text { status }\end{array}$ & $\begin{array}{l}\text { Age } \\
\text { (months) }\end{array}$ & $\begin{array}{l}\text { Sick since } \\
\text { birth? }\end{array}$ & $\begin{array}{l}\text { Other } \\
\text { illness at } \\
\text { admission }\end{array}$ & Sex & Caregiver & $\begin{array}{l}\text { Age } \\
\text { (years) }\end{array}$ & $\begin{array}{l}\# \text { of } \\
\text { kids }\end{array}$ & $\begin{array}{l}\text { Marital } \\
\text { status }\end{array}$ & $\begin{array}{l}\text { Education } \\
\text { level } \\
\text { (completed) }\end{array}$ & $\begin{array}{l}\text { Employment } \\
\text { status }\end{array}$ & \\
\hline \multicolumn{13}{|l|}{ Urban } \\
\hline $\mathrm{HH} 52$ & SAM & 14 & $\begin{array}{l}\text { Yes (Cough, } \\
\text { fever) }\end{array}$ & $\begin{array}{l}\text { Diarrhea, } \\
\text { fever, } \\
\text { pneumonia }\end{array}$ & Girl & Mother & 20 & 3 & Married & Illiterate & Housewife & Nuclec \\
\hline $\mathrm{HH} 53$ & SAM & 6 & $\begin{array}{l}\text { Yes (Fever, } \\
\text { cough) }\end{array}$ & Diarrhea & Boy & Mother & 20 & 1 & Divorced & Primary & None & Extenc \\
\hline HH55 & SAM & 4 & Yes (Fever) & $\begin{array}{l}\text { Diarrhea, } \\
\text { vomiting }\end{array}$ & Girl & $\begin{array}{l}\text { Maid } \\
\text { servant }\end{array}$ & 19 & 1 & Married & Primary & $\begin{array}{l}\text { Garment } \\
\text { worker }\end{array}$ & Nucleč \\
\hline HH57 & SAM & 4 & $\begin{array}{l}\text { Yes (Fever, } \\
\text { cough) }\end{array}$ & $\begin{array}{l}\text { Diarrhea, } \\
\text { cough, } \\
\text { fever }\end{array}$ & Girl & Mother & 16 & 1 & Married & Primary & Housewife & Extenc \\
\hline $\mathrm{HH} 51$ & MAM & 8 & $\begin{array}{l}\text { Yes } \\
\text { (Coldness, } \\
\text { diarrhea) }\end{array}$ & $\begin{array}{l}\text { Diarrhea, } \\
\text { fever, oral } \\
\text { thrush }\end{array}$ & Boy & Mother & 17 & 1 & Married & Primary & Housewife & Nuclec \\
\hline HH59 & MAM & 4 & $\begin{array}{l}\text { Yes (Fever, } \\
\text { coldness) }\end{array}$ & $\begin{array}{l}\text { Diarrhea } \\
\text {,fever }\end{array}$ & Girl & Mother & 17 & 1 & Married & Primary & Housewife & Extenc \\
\hline $\mathrm{HH} 60$ & SAM & 8 & $\begin{array}{l}\text { Yes } \\
\text { (Coldness) }\end{array}$ & $\begin{array}{l}\text { Diarrhea, } \\
\text { pneumonia }\end{array}$ & Girl & $\begin{array}{l}\text { Mother } \\
\text { in low }\end{array}$ & 35 & 3 & Married & Illiterate & $\begin{array}{l}\text { Small } \\
\text { restaurant } \\
\text { business }\end{array}$ & Nuclec \\
\hline $\mathrm{HH} 62$ & MAM & 4 & Yes(Diarrhea) & $\begin{array}{l}\text { Diarrhea, } \\
\text { severe } \\
\text { respiratory } \\
\text { distress }\end{array}$ & Boy & Mother & 35 & 3 & Married & Illiterate & Housewife & Nucleč \\
\hline $\mathrm{HH} 63$ & SAM & 7 & $\begin{array}{l}\text { Yes } \\
\text { (Breathing } \\
\text { difficulties, } \\
\text { fever) }\end{array}$ & $\begin{array}{l}\text { Diarrhea, } \\
\text { pneumonia }\end{array}$ & Girl & Aunt & 19 & 1 & Divorced & Secondary & - & $\begin{array}{l}\text { Extenc } \\
\text { family }\end{array}$ \\
\hline \multicolumn{13}{|l|}{ Rural } \\
\hline \multirow[t]{2}{*}{ ID } & \multicolumn{6}{|c|}{ Children characteristics } & \multicolumn{5}{|c|}{ Mothers characteristics } & House \\
\hline & $\begin{array}{l}\text { Nutritional } \\
\text { status }\end{array}$ & $\begin{array}{l}\text { Age } \\
\text { (months) }\end{array}$ & $\begin{array}{l}\text { Sick since } \\
\text { birth? }\end{array}$ & $\begin{array}{l}\text { Other } \\
\text { illness at } \\
\text { admission }\end{array}$ & Sex & Caregiver & $\begin{array}{l}\text { Age } \\
\text { (years) }\end{array}$ & $\begin{array}{l}\text { \# of } \\
\text { kids }\end{array}$ & $\begin{array}{l}\text { Marital } \\
\text { status }\end{array}$ & $\begin{array}{l}\text { Education } \\
\text { level } \\
\text { (completed) }\end{array}$ & $\begin{array}{l}\text { Employment } \\
\text { status }\end{array}$ & $\begin{array}{l}\text { Family } \\
\text { structi }\end{array}$ \\
\hline $\mathrm{HHO} 4$ & SAM & 10 & $\begin{array}{l}\text { Yes } \\
\text { (Diarrhea, } \\
\text { fever) }\end{array}$ & $\begin{array}{l}\text { Diarrhea, } \\
\text { fever }\end{array}$ & Girl & Mother & 20 & 3 & Married & Secondary & Housewife & Extenc \\
\hline $\mathrm{HH} 08$ & SAM & 5 & $\begin{array}{l}\text { Yes(diarrhea, } \\
\text { urine } \\
\text { infection) }\end{array}$ & $\begin{array}{l}\text { Diarrhea, } \\
\text { vomiting }\end{array}$ & Boy & Mother & 26 & 2 & Married & Secondary & Housewife & Extenc \\
\hline $\mathrm{HH} 12$ & SAM & 9 & Yes (fever) & Diarrhea & Girl & Mother & 23 & 2 & Married & Secondary & Housewife & Nucleć \\
\hline Hh10 & SAM & 14 & $\begin{array}{l}\text { Yes(fever, } \\
\text { coldness) }\end{array}$ & $\begin{array}{l}\text { Diarrhea, } \\
\text { fever }\end{array}$ & Girl & Mother & 35 & 3 & Married & Secondary & Housewife & Nucleé \\
\hline $\mathrm{HH} 01$ & MAM & 11 & $\begin{array}{l}\text { Yes (cough \& } \\
\text { coldness) }\end{array}$ & $\begin{array}{l}\text { Diarrhea, } \\
\text { fever }\end{array}$ & Boy & Mother & 23 & 3 & Married & Secondary & Housewife & Extenc \\
\hline $\mathrm{HH} 02$ & MAM & 6 & Yes (fever) & $\begin{array}{l}\text { Diarrhea, } \\
\text { fever }\end{array}$ & Boy & Mother & 24 & 2 & Married & Secondary & Housewife & Nucleć \\
\hline $\mathrm{HH} 03$ & MAM & 11 & $\begin{array}{l}\text { Yes (Fever \& } \\
\text { urine } \\
\text { problem) }\end{array}$ & $\begin{array}{l}\text { Diarrhea, } \\
\text { vomiting }\end{array}$ & Girl & Mother & 25 & 2 & Married & Primary & Housewife & Nuclec \\
\hline
\end{tabular}




\begin{tabular}{|lllllllll} 
HH05 MAM 16 & $\begin{array}{l}\text { Yes } \\
\text { (Coldness, } \\
\text { pneumonia \& } \\
\text { diarrhea) }\end{array}$ & $\begin{array}{l}\text { Diarrhea, } \\
\text { vomiting }\end{array}$ & Girl & Mother & 33 & 3 & Married Secondary Housewife & Extenc \\
& & &
\end{tabular}

\section{Children's treatment-seeking trajectories and health outcomes: an overview}

Most family members of the 17 children reported that children had been ill for some time prior to admission in icddr,b hospitals. There had also been significant treatment-seeking efforts by the time of admission, including many having visited drug sellers, healers, private doctors and public hospitals (Table 2). Many family members in both rural and urban areas reported trying several of these treatment-seeking options sequentially or in parallel.

Table 2 Treatment-seeking patterns for the index child's illness pre-admission

\begin{tabular}{|c|c|c|c|c|c|}
\hline & Rural & & Urban & & Total \\
\hline & SAM $(N=4)$ & MAM $(N=4)$ & SAM $(N=6)$ & $\operatorname{MAM}(\mathrm{N}=3)$ & $N=17$ \\
\hline Visited a healer pre admission & 4 & 4 & 2 & 1 & 11 \\
\hline Visited a drug seller pre admission & 4 & 4 & 4 & 1 & 13 \\
\hline Visited another facility/doctor pre-admission & 2 & 4 & 5 & 2 & 13 \\
\hline Visited a CHW pre admission & 0 & 3 & 0 & 0 & 3 \\
\hline Was admitted in another facilities before coming to icddrb hospital & 1 & 2 & 0 & 1 & 4 \\
\hline
\end{tabular}

During initial hospitalization, we observed that hospital health workers teach the child's caregiver about food preparation and preservation processes and complementary feeding practices such as maintaining minimum dietary diversity, meal frequency, using a spoon instead of fingers or a bottle for feeding, and avoiding drinking cold food/water. They also organize demonstration sessions on breastfeeding, hand washing, and using treated water for cooking and drinking purposes. The need to maintain hygienic practices to support early recovery and prevent new illnesses is emphasized. On discharge, hospital health workers were also seen to advise caregivers to continue with prescribed medicine, complete vaccines, breastfeeding (noting that employed mothers can store breast milk), and feeding homemade food. In addition, hospital health workers gave caregivers their mobile phone number so that they could be contacted for post-discharge communication and to prescribe any further medicines needed.

13 of the 17 children had fully recovered by the time we completed our interviews; 4 had died ( 3 in the urban site and 1 in the rural). One of the children who died did so before discharge. Two of the 16 children discharged alive had been discharged from the icddr,b hospitals against medical advice (one per site, both SAM). Post-discharge, most parents reported that children took time to recover, with many experiencing new episodes of illness. Eight visited a healer over the post-discharge period, 14 a drug seller, and nine another health facility. 11 were re-admitted either back to icddr,b or into another hospital (Table 3 ).

Table 3 Discharge and post-discharge treatment-seeking patterns for the index child's illness

\begin{tabular}{|lllllc|}
\hline & Rural & & Urban & Total \\
\hline Recovered & SAM $(\mathrm{N}=4)$ & MAM $(\mathrm{N}=4)$ & SAM $(\mathrm{N}=6)$ & MAM $(\mathrm{N}=3)$ & $\mathrm{N}=17$ \\
\hline Discharged against advice & 3 & 4 & 4 & 2 & 13 \\
\hline Visited a healer post-discharge & 1 & 0 & 1 & 0 & 2 \\
\hline Visited a drug seller post- discharge & 2 & 3 & 2 & 1 & 8 \\
\hline Visited another facility/doctor post discharge & 2 & 4 & 4 & 3 & 14 \\
\hline Visited a CHW post-discharge & 0 & 0 & 4 & 3 & 9 \\
\hline Was re-admitted & 1 & 3 & 1 & 0 & 3 \\
\hline
\end{tabular}

The caregivers of selected children mentioned more treatment-seeking actions and greater use of traditional healers. This difference was also observed between quantitative and qualitative responses for our selected participants, suggesting greater openness and amount of detail in the latter, as would be anticipated.

In subsequent sections, we highlight key influences and impacts on post-discharge treatment-seeking and recovery. However, to illustrate complexities of treatment-seeking patterns and influences, and the interplay of vulnerabilities and abilities, we first present two contrasting household stories: one from an urban and one from a rural household (Boxes 1 and 2). These stories also show how the admission and post-discharge experience for children is inextricably linked to their pre-admission situation and experience. 
Box 1- Story of a rural child aged 14 months with SAM in Bangladesh (HH10)

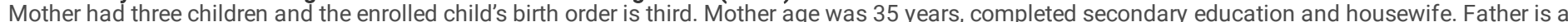

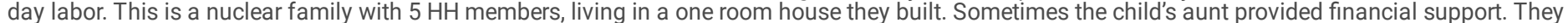

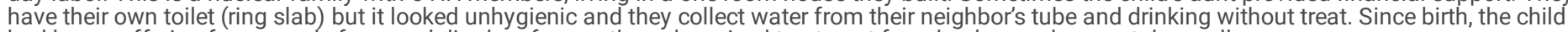
had been suffering from cough, fever and diarrhea frequently and received treatment from healers and nearest drug sellers.

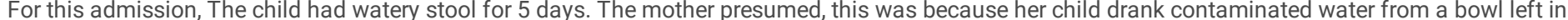

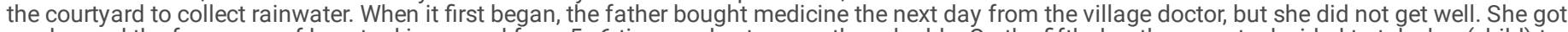

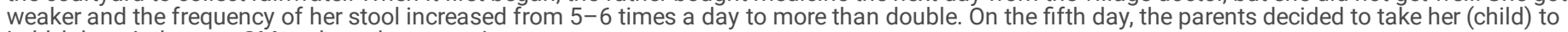
icddr,b hospital as per GM and aunt's suggestion.

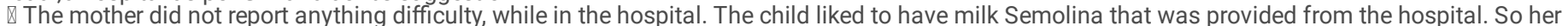

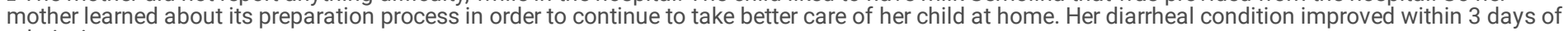
admission.

$\nabla$ Before discharge the mother was again counseled about food preparation, feeding practices, child caring, hygiene practices and basic medicine administration procedure. Nurses gave some medicine to continue after discharge.

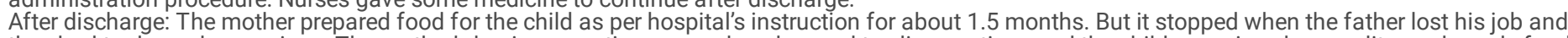

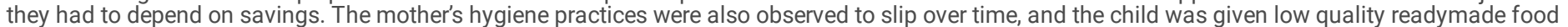
because she refused to take the homemade ones.

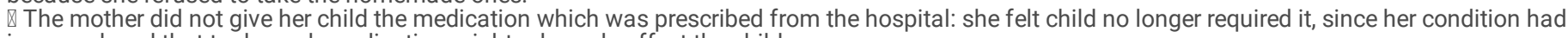
improved, and that took much medication might adversely affect the child.

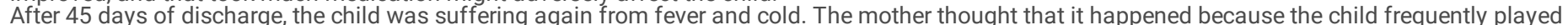

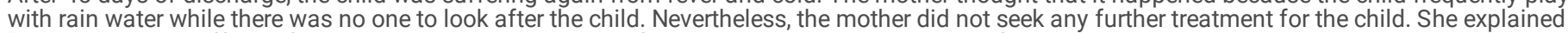

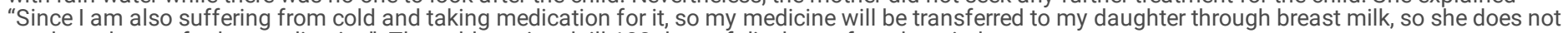
need to take any further medication". The cold persisted till 180 days of discharge from hospital.

\section{Box 2 - Story of an urban child aged 6 months with SAM in Bangladesh (HH53]}

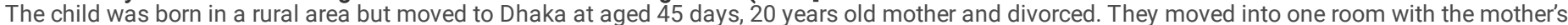



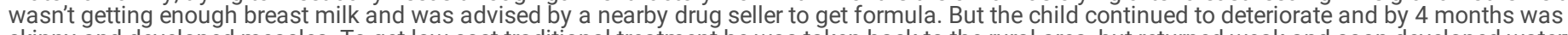

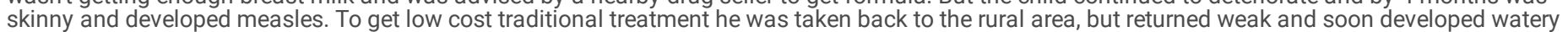

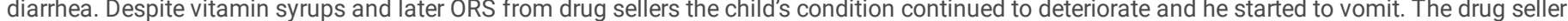
referred the child to a hospital, where he was referred on to icddr,b and admitted.

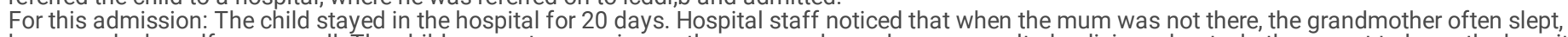

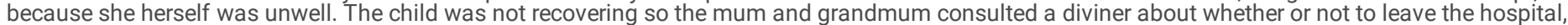

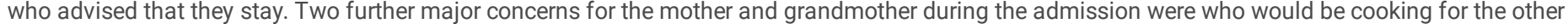
household members at home, and the child's father phoning the mum to say, "if anything happens to my son, I will sue you".

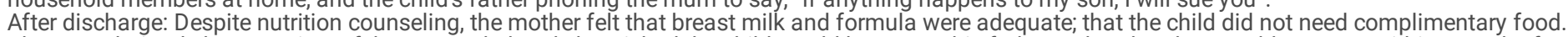

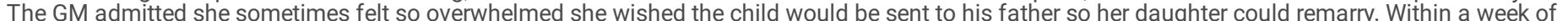

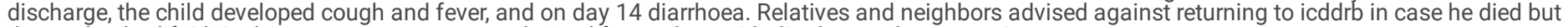
the mother had faith in them so went. He was re-admitted for 12 days with diarrhea and pneumonia.

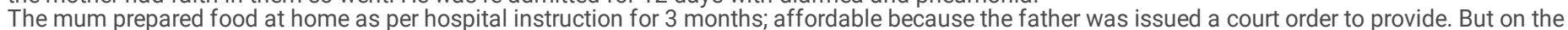

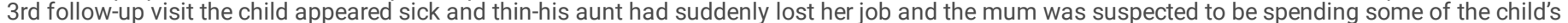
money from the father on herself. His cold at the time was considered by her not to a big problem as he'd had it since birth so he would recover. Unfortunately, the child died not long afterwards.

[Boxes 1 and 2 to be placed here]

\section{Socio-cultural and environmental influences on treatment-seeking and outcomes}

\section{Mothers' workload in homes and levels of support from others}

Many rural and urban women had very heavy household workloads, including cooking and serving meals, washing clothes, rearing domestic animals, and harvesting rice in the paddy fields. Mothers' need to return to their household work was reported to be an important influence on their decision to discharge their ill children against medical advice. Parents generally felt that since their child's condition was improving, and was no longer life-threatening, it was a greater priority to get home to their other responsibilities than to stay in the hospital for an additional few days. As one mother explained:

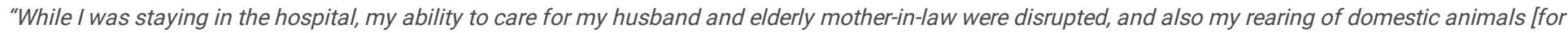
income]. So, I decided I had to take my child home against the doctor's advice." Mother, Rural. $\mathrm{HH} 5$.

These workloads also made it challenging for mothers to adhere to nutrition, hygiene, and treatment advice at home and to bring their children back to the hospital or facilities as advised.

Mothers who were able to keep their children in hospital for the recommended period, and to adhere to advice post-discharge, were able to draw on support from other family and community members during hospitalization and post-discharge, with assistance most often coming from husbands, older children, other close relatives, and female neighbors.

Practical support from female relatives and friends was particularly important. For example, four rural mothers visited their own mothers' home in the immediate post-discharge period to get support from grandparents and aunts in providing medicine, and preparing and providing food as per hospitalphysician advice. In one case ( $\mathrm{HH} 08)$, a maternal grandmother and aunt visited the child's home to assist the mother with household chores as the mother focused on the child's care. Some husbands were also reported - and observed - to assist practically:

"I and my wife have decided to work outside of the home at different times to take care of our child properly. So, I work at night when my wife can take care of my child and my wife works during the day when I can stay at home to take care of my child. I think that both of us need to work to fulfill our basic needs properly and it's important to look after our child as we love her very much."Father, Urban, HH55.

In the rural HH12's case, a close relative who resides nearby a health facility had guided the parents of the child over mobile phone to re-admit their ill child in an urban private hospital in order to get what was perceived as better treatment. 
Family and friends were clearly an important source of information and advice for mothers when their children remained sick or did not recover at the desired pace. Some urban mothers were new to the area and therefore unfamiliar with the locality, and so relied particularly heavily on longer term residents' advice. While some advice was to seek prompt care from trained medical practitioners or from government health care facilities, many mothers reported following advice to purchase medications from drug sellers or general shops or to simply dress their children more warmly. Common purchases for diarrhea were oral saline, and for coughs and fevers were Napa syrup (Paracetamol).Some advice entailed the use of traditional medicines or treatments, as described further below in the beliefs around etiology of illness and related treatment.

\section{Abuse of mothers by family members and reported links to depression}

Even with support of others, mothers described having to achieve a challenging balance between adequately fulfilling household chores and child care responsibilities with putting aside a specific time and effort to support the discharged child's recovery. Several expressed concern about the difficulty of maintaining their relationships with their husbands and their reputation in the wider household and community. As one mother explained:

"Since I have to cook meals three times a day, serve food to others, [and] clean the households and clothes, it is really difficult for me to [also] provide food and medicine, breastfeed, and bath my child on time. After doing household chores all day long, I am so tired, particularly at night, and often feel ill, which adversely affects the health care of my child. Unfortunately, my husband blames my improper childcare for my child's illness. And if I say something to retaliate against my husband's comments, others might treat me as a bad woman or wife." Mother, Urban. HH52

Several mothers directly attributed their child's failure to recover quickly to their difficulty in managing all of these tasks. One talked about her child being exposed to rain and cold as a result of her work, and another about hiding her child's condition from others out of a concern about being blamed for it. Notable was that four different mothers openly reported that their child's failure to recover resulted from their own exposure to mental and physical abuse from their husbands and mother-in-laws. As one mother described:

"My husband often beats me unnecessarily when drunk or when I do not provide the amount of money he has demanded from my father's home. So I am really reluctant to provide medicine and food in time [for the discharged child] as per hospital-physician advice [because he will think I have more money I am hiding]. I think my husband dislikes me very much and wants our separation." Mother, Urban, HH5

Three other mothers reported being told by husbands after the child's discharge not to give medicines at home, or not to leave home to go to health facilities. Such instructions may be based on jealousy of mothers' potential interactions with other men, or concern that the treatment is an unnecessary cost. Two of these mothers reported having been beaten previously by their husbands for taking their children to medical practitioners despite having been forbidden. They were fearful to do so again. Mothers reported that this abuse, and fear of it, led to them being depressed, and to marital separations, both of which reduced their affection and attention towards the care of their ill children.

\section{Beliefs about the etiology of illness and perceptions about the usage of medicines}

Some parents were aware of key danger signs and child illness symptoms, and their prevention and treatment, with many discussing have learned about this during their child's hospitalisation. Several also mentioned having learned about this through a television documentary broadcast by the Government's Ministry of health and family welfare.

While many family members made significant efforts to follow the discharge advice given at icddr,b hospitals, it was clear that some felt that the child's illhealth was caused by a range of alternative causes rather than biomedical or nutritional explanations. For example, there were descriptions of children's failure to recover or a new illness being caused by a supernatural air having a spiritual power over the child, or by a child being affected by an 'evil eye' cast by someone in the community (including via the mother through breastmilk). A mothers' spicy diet was also felt by some to result in diarrhea in their breastfeeding child.

"My child suffered from diarrhea because I ate spicy food which was transmitted to the body of my child through breastfeeding. So I discontinued breastfeeding my child." Mother, Rural. HHO7

Beliefs about what caused the child's ill health, together with advice of family, friends and neighbors, influenced treatment-seeking decision-making and action. For example, a child believed to have diarrhea caused by an evil eye was taken to a spiritual healer who provided a blessed metal object to tie around the neck and hands of the children or mothers. Children believed to have diarrhea caused by supernatural air were given herbal medicines and sacred water to drink. As with the above example, some mothers opted to discontinue breastfeeding and switched to formula milk.

\section{Households' environment: water, sanitation and hygiene practices}

Children's family members and community representatives felt that household and community environments undermined children's recovery, particularly in the densely populated urban slums where there is poor waste management, drainage and ventilation.

"Please let's see in the slum: a discharged child is walking and playing with the dirty logged water and sometimes putting water into her mouth. In this area, we often have water trapped after rain because of the inadequate drainage systems. And the water is filthy, contaminated by dirty things such as open sewers, urine, and home debris. Sometimes we even see open stool in the water. Can you imagine how dangerous that is for children?." Community health worker, Urban, KII-51

In these very challenging social and physical environments, some caregivers were observed to have less-than optimal hygiene practices that may have contributed to the spread of diseases; for example using toilets while barefoot, and washing hands without using soap before going on to feed children: 
"The mother left the child with an older kid and went to the toilet barefoot. Having used it she went to the tap and ... washed her hands and legs using only water [no soap]. Then she went to the kitchen for cooking and after 20 minutes came back to the living room and started feeding food to her child." Household observation, Urban, $\mathrm{HH} 55$

\section{Economic influences on treatment-seeking and outcomes}

In the majority of the households, where money was needed or costs were incurred across the treatment-seeking pathway, the father of the child was generally considered to be responsible for meeting such costs. Men played a more prominent role in supporting mothers financially than assisting with other forms of support. Where the sick child's father was absent, or was unable or did not want to assist, the range of relatives highlighted in the previous section were important. As one mother mentioned:

"My father sends money (2500 BDT) to me for treatment for my child, as he knows well about the financial inability of child's father for treating the child." Mother, Rural, HH5

Mothers in particular had very little access to money in homes, and where they earned an income this was primarily through casual and informal work. Many families were largely living 'hand to mouth', juggling multiple demands on their cash, with few savings to draw upon. This influenced their choice of action:

"I have to find money for accommodation, food and clothes from my limited [regular] income. A sudden treatment and transportation cost to bring the child to the hospital is an extra burden for me. The situation is the worst fifteen days into a month when my payment has been used up and when I'm under pressure to repay loans. [so with the child's illness] we went for low-cost treatment from the nearest drug shop." Mother, Urban. HH53

In contrast with private facilities which are relatively expensive, the free treatment offered at icddr,b - together with the institution's services and reputation for quality care - were reported by many family members as a major incentive to seek care there when it was needed post-discharge. Despite this, mothers still faced affordability challenges as a result of transport costs to the facility and the need to purchase basic necessities not required when staying at home. Concerns about these direct and indirect costs, layered on top of the previous treatment-seeking action costs, contributed to some parents discharging their children against medical advice (particularly in the urban area), and to parents being hesitant to bring their children back to hospital post-discharge. As one mother mentioned:

"I did not communicate with the hospital physician of icddr,b using the mobile phone number I was given because I thought they may request us to go there and be re-admitted. We did not have enough cash to pay for travel to the hospital and to cover other costs needed during admission. The costs we'd already had to meet before the admission [initial hospitalization] were the reasons we were short of cash already and I could not manage to find the money we would need from neighbors and local NGOs because we had recently moved from the rural area [so didn't have anybody to approach]." Mother, Urban, HH62

Nonetheless, some families were able to navigate around these challenges of indirect costs by communicating among themselves and with health workers via phone as illustrated in the following quote:

"I explained clearly over the mobile phone to the child's father about the loose stool. He brought oral saline straight after consulting with a doctor. I think this is cost-effective for us as we did not have to pay any transport costs to see the doctor and it was a time saving solution also." Mother, Urban, HH59

Public hospitals, although officially free, were reported by some to require informal payments, such as a small financial incentive to ensure children are seen during ward rounds. Also, physicians in some public hospitals were reported to encourage unnecessary but relatively expensive diagnostic tests or medicines outside the hospital, and there were some reports of brokers being employed by public doctors to attract families to private facilities. As a rural community health worker explained:

"Some physicians of public hospitals nominate people [such as village doctors, rickshaw puller/transport drivers, or hospital health workers] to motivate the parents of the children on the way to the hospital and even during re-admission to bring the patient to the physician's private facility. Sometimes they [public hospital physicians] prescribe unnecessary diagnostic tests and poor quality medicines because they are incentivized to do so by the diagnostic center and drug company. [Some parents are aware of these practices] and so are reluctant to seek treatment from public hospitals." Community representative, Rural. KII68

Families' treatment-seeking stories suggest that a major reason for treating children at home, or for seeking treatment from untrained medical practitioners (such as drug sellers and healers) - even when recognizing that the care might be sub-standard - is a concern about anticipated costs from hospitals.

Mothers' need to return to their income-earning tasks and to make up for income loss during admission contributed to their need for support from others to care for their child post-hospital discharge.

\section{Health system factors influencing treatment-seeking and outcomes}

Costs related to the health system and their influence on treatment-seeking and recovery have been alluded to in the previous section. Also important at the health system level are the perceived quality of care at facilities, and - although raised more by health workers than family members - the reportedly heavy use of antibiotics in many households and communities.

Regarding the perceived quality of care, in general, family members described being very happy with their children's care in icddr,b hospital. In particular, they appreciated being asked directly about the child's illness history from health workers, and the supportive and respectful interaction with them in the counseling and demonstration sessions for breastfeeding, complementary feeding and hygiene practices. Many family members mentioned that these sessions improved 
their health care knowledge and encouraged them to adhere to the treatment advice, and that their new knowledge supported their children's recovery. For example, three mothers felt that their children's diarrhea cases had eased off because they now wash their hands with soap, and have switched from bottle feeding to feeding with a clean spoon.

This was in contrast to reports of care received in public hospitals. For example, mothers in three homes who had children re-admitted to a public hospital reported being upset that physicians prescribed medicines based only on talking to the duty nurses rather than to the mothers themselves; as mothers they felt they had a far better understanding of the child's history than the nurses. Such observations and concerns among mothers undermined their trust in the quality of care being offered, and contributed to their discharging their own children against medical advice and taking them either home or for treatment elsewhere. As one father explained:

"Physicians of the public hospital in Dhaka city are not serious enough to provide good quality care through enough attention and proper interaction with us. This happens because the physicians think that it's usually only poor patients that come to this hospital, and their families do not have any political power. Besides, the physicians in Dhaka city are really powerful themselves. So they know nothing will happen [to them], even if a child dies because of their improper treatment." Father, Urban, HH57

Over-use of antibiotics was regularly raised by health care workers as a factor influencing recovery, and as resulting from treatment-seeking actions and advice to family members from friends, neighbours and improperly trained or motivated health providers. Hospital health workers were concerned about treatment failure among some children during re-admission due to the unnecessarily high use of antibiotics prior to admission. Many private physicians and drug sellers were perceived to provide these too early in an effort to build their reputation (and profit) in the community through children getting better fast, and to switch the type of antibiotic far too often. Community medical practitioners of public health care facilities felt that they could not compete with these fastacting drugs given their recommendation of relatively long treatment courses. Another related challenge is that even where the physicians do not prescribe antibiotics, many family members buy them over-the-counter anyway as they are unaware of the potential individual and public health harms of overuse.

\section{Discussion}

As part of a larger inter-disciplinary study, we conducted a qualitative social science study to understand the admission and post-discharge treatment-seeking and recovery experiences of families of undernourished children aged 2-23 months admitted in two icddr,b hospitals in Bangladesh. We gathered perspectives of family members of admitted children to complement past and on-going quantitative data on risk factors for mortality post-discharge. We used a conceptual framework (Figure 1) to explore patient and provider perspectives of socio-cultural and environmental, economic and health system influences related to opportunities and challenges of post-discharge recovery and treatment-seeking behavior.

Overall, we identified several important opportunities related to treatment-seeking and recovery from the perspective of family members of admitted children. These include: positive and supportive interactions between health workers and caregivers (including valued advice being given through face-to-face information and sessions and phone consultations); free treatment at the study hospitals; and financial and practical support to mothers from family members, other relatives and neighbours. Challenges for treatment-seeking and recovery were mothers having to juggle multiple domestic responsibilities in addition to caring for the child, difficulties in accessing funds, and the lack of support from the child's father and others. In some cases the latter was related to mothers being concerned about being stigmatized for being a 'bad mother' or 'bad wife', or physical violence. These challenges were often in the context of unhealthy physical environments and in homes without easy access back to care. We discuss three cross-cutting issues in more detail: early discharge from hospital against medical advice; post-discharge treatment-seeking behavior and recovery; and concerns about inappropriate use of antibiotics. In a separate paper, we explore the gender issues and influences in more depth, given that contextually relevant gender analyses are needed to improve health-related interventions, programs and policies [35, 36].

Early discharge from hospital against medical advice is significantly associated in Bangladesh as in other developing countries with higher post-discharge mortality and re-admission [4,6,37]. In line with a previous study conducted at icddr,b hospitals [4], we found that mothers who were taking their children home against medical advice were doing so for a range of inter-related reasons, including a view that the child had either recovered enough to go home (ie the child's condition was improving or he/she had recovered from the primary illness), or was not going to recover and so should be taken home. Further reasons identified through this study included mothers' or other family members' concerns about other children and chores at home, worries about indirect costs of admission and - especially in the urban setting - loss of income during admission. Mothers who were able to keep their children in hospital until formally discharged were following advice given during the admission, often with financial and practical support from family members, female neighbors and close relatives. This group was energized by observing their child's continued recovery. In the study hospitals, conditional cash transfers (CCT) targeted at the most vulnerable children or households may help to reduce early discharge by addressing some of the indirect and opportunity costs (such as costs to do with for example transport costs and loss of income respectively) [38]. Nevertheless, important questions remain around sustainability and cost-effectiveness of such programmes, even where they are shown in trials to have a positive impact [38,39].

In some settings, discharge of children against medical advice has been reported to result from inadequate beds, conflict between parents and staff, lack of medicines or food in hospitals, and from high admission costs $[2,8,11]$. Caregivers voiced concerns such as these in relation to public hospitals in Bangladesh (where parents reported that they had discharged their children early because of concerns about informal charging and poor quality of care), but we did not hear about this in the study hospitals, where family members' descriptions of care were much more positive. These findings need checking with a specifically designed study. However, they suggest that important potential interventions in public hospitals may include initiatives that reduce any unnecessary referral to relatively expensive private facilities and that reduce 'informal payments' (i.e. contributions that are additional to those stipulated in institutional policies). Initiatives that increase the presence of health workers in hospitals and that improve health worker-parent communication may also be needed. 
With regards to treatment-seeking and recovery post-discharge, adherence to advice given in hospitals is vital. Past studies at icddr,b hospitals in Bangladesh have found that failure to follow advice was associated with mortality of children post-discharge; specifically care-seeking from traditional healers, and failing to contact the hospital physician by mobile phone in an emergency as advised [4]. Many mothers valued the advice they were given during the admission period and on discharge, and were able to follow it post-discharge. However, we noted several other reasons that families fail to follow advice, even where that advice appears to be given well and instructions are demonstrated and appreciated. Important immediate factors included mothers returning to busy workloads in homes, and - particularly in urban areas - mothers needing to earn an income. These responsibilities made it challenging for mothers to offer childcare as advised, and often led to mothers having to hand over care to others in households who may not be as well informed or motivated as mothers to adhere to advice. These caregivers, together with (often male) decision-makers in homes, are influential in what care children receive, and when and where follow-up care is sought, making it challenging for mothers to exert their demands. These findings highlight the importance wherever possible of including significant others - in particular children's fathers and grandfathers - in health education messaging targeting the post-discharge period. Although we did not examine advice and adherence at public hospitals, broader comments in interviews on poor interpersonal communication suggest this might be an issue. This needs to be specifically examined, given that these facilities serve the majority of the Bangladesh population.

We found that additional factors influencing adherence to advice post-discharge, as also noted in other studies [2,4], were physical and financial access to health facilities. Elsewhere, we have highlighted that this is a particularly an issue given the need to recoup initial admission costs, and where household decision-makers are reluctant to allow their wives to have interactions with males health providers [16, 35]. Being able to seek emergency advice by phone potentially eases such challenges. The families we talked to post-hospital discharge highly valued having the option to receive emergency advice by mobile phone. Although one family opted against this advice because of concerns about opportunity costs, for some families the ability to discuss the child's situation contributed to significant cost-savings. There is currently widespread interest in Bangladesh and elsewhere in offering advice and support by mobile phones to strengthen adherence to advice in resource-poor settings [4, 40-46]. A recent pilot study in Bangladesh has suggested that mobile phones are a feasible and acceptable option for changing perceptions on nutrition among low-income rural families [46]. We support others [4] that a health worker or community health worker maintaining mobile contact with families of vulnerable children has the potential to support post-discharge adherence to treatment advice, as part of a wider set of interventions.

Inappropriate use of antibiotics by family members and untrained health providers were regularly raised as a concern by health workers in our study, but less so by family members. As has been documented in other settings [47], family members were generally keen to access antibiotics for early recovery of their children, appreciating their convenience, perceived effectiveness and associated savings. Overuse of antibiotics is a major concern globally, contributing to antimicrobial resistance and to increasing costs for families, health systems and for public health more generally [48]. Bangladesh has an estimated 100 000 licensed retail drug shops and a further 100000 unlicensed drug shops selling prescription-only drugs including antibiotics [49]. Polypharmacy, or the prescribing of 3 or more drugs, is common across urban and rural health facilities ( $46 \%$ and $33 \%$ of users respectively) [50]. Providers are responding as elsewhere to customer demand, habits and profit [51], as well as to pharmaceutical companies' strategies of assigning medical representatives to motivate physicians through inducements, persuasion, and emotional blackmail to prescribe antibiotics so that they can achieve individual and company targets [49, 52]. We agree with others $[49,50]$ that it is crucial to sensitize parents, medical practitioners and drug sellers regarding the use, prescription and selling of antibiotics particularly for infants and young undernourished children. Given the rest of our findings, such initiatives must be complemented by other interventions that tackle the multiple socio-cultural and environmental, economic, and health system factors that interact to influence family members to choose this relative cheap and easily accessible form of treatment.

\section{Strengths and limitations of the study}

We collected data using multiple qualitative data-collection techniques including individual interviews, observations, and group discussions in two research hospitals, communities, and households of children who had been admitted. Although we only interviewed family members of 17 children, repeated interviews in homes helped us build trust with family members and access rich accounts of the treatment-seeking journeys they had followed for their children. Using multiple methods helped us to understand different perspectives and triangulate findings, and through including an urban and rural site, we were able to see some similarities and differences across very different settings in Bangladesh. Future publications will merge quantitative and qualitative CHAIN data, and include cross-country comparative work.

Although, we did not gather in-depth data from public hospitals, we often heard about experiences in public hospitals. These discussions suggested that many of our findings are highly applicable to those hospitals. However, a specifically designed study is necessary to explore this in depth, and identify potential interventions for public hospitals.

\section{Conclusion}

Children's caregivers, usually mothers, navigate diverse socio-cultural and environmental, economic and health system challenges in their post-discharge treatment-seeking for their children. These challenges intersect to present complex layered vulnerability to early discharge of children from hospital against medical advice, to non-adherence to follow-up advice, and to provider concerns about an inappropriately high use of antibiotics. Particularly important influences on treatment-seeking and recovery were levels and types of advice and support given by health workers and family members (in hospitals and in homes respectively), access to funds, and costs of care.

Many treatment-seeking actions indicate parents' efforts and agency that might be built upon to improve outcomes. However, this agency is constrained by difficult family situations and broader structural drivers such as low access to income and gender roles and relations. Interventions with potential to build on parents' agency and reduce children's vulnerability to poor outcomes include: strengthening information giving during hospitalization on what post-discharge care is needed and why, and on the risks associated with delays in follow ups and mis-use of antibiotics; initiatives to reduce direct and indirect costs

Page $11 / 15$ 
associated with (re)visiting hospitals (including carefully designed cash transfer initiatives); engaging fathers and other influential family-members in discussions on post-discharge advice; and building mobile phone-based support for follow-up care. Given intersecting influences and vulnerabilities, interventions must be integrated.

\section{Abbreviations}

CHAIN - Childhood Acute Illness and Nutrition Network

icddr,b-International Centre for Diarrhoeal Disease Research, Bangladesh

LMICs-Low and Middle-Income Countries

SAM-Severe Acute Malnutrition

MAM-Moderate Acute Malnutrition

CC-Community Clinic

CHCP-Community Health Care Providers

CHW-Community Health Workers

NGO-Non-Governmental Organizations

HDSS-Health and Demographic Surveillance System

ICU-Intensive Care Unit

NRU-Nutrition Rehabilitation Unit

HH-Household

BDT- Bangladesh Taka

CCT- Conditional Cash Transfers

\section{Declarations}

\section{Acknowledgements}

The authors thank all study participants, the Childhood Acute Illness and Nutrition Network and field workers for their valuable cooperation and support when conducting the study. icddr,b is grateful to the Government of Bangladesh, Canada, Sweden, and the UK for providing core/unrestricted support.

\section{Authors' information}

Md. Fakhar Uddin (MFU) with a degree Master of Social Science in Anthropology, he was Principal Investigator of this study. He (MFU) is highly experienced and trained in conducting qualitative research, working under the Nutrition and Clinical Services Division of icddr,b, Dhaka, Bangladesh. Sassy Molyneux (SM) with a PhD was Co-Principal Investigator of this study. She (SM) is a Professor of University of Oxford and working at KEMRI-Wellcome Trust Research Programme, Kilifi, Kenya. Kui Muraya (KM) with a PhD, she is a Social Scientist and working at KEMRI-Wellcome Trust Research Programme, Nairobi, Kenya. Julie Jemutai (JJ) with a PhD, she is working at KEMRI-Wellcome Trust Research Programme, Kilifi, Kenya. James A. Berkley (JAB) with a PhD was CoPrincipal Investigator of this study. He (JAB) is a Professor of University of Oxford and working at KEMRI-Wellcome Trust Research Programme, Kilifi, Kenya. Judd L. Walson (JLW) with a PhD, he is a Professor of Departments of Global Health, Medicine, Pediatrics and Epidemiology, University of Washington. Md. Alamgir Hossain (MAH) and Md. Aminul Islam (MAl) with a degree Master of Social Science (MSS) in Anthropology, they (both male) had worked as a Research Officer in this study under the Nutrition and Clinical Services Division of icddr,b. Scholastica M. Zakayo (SMZ) and Rita Wanjuki Njeru (RWN) with good track records in conducting qualitative research, they (both female) are social scientists and working at KEMRI-Wellcome Trust Research Programme, Kilifi, Kenya. Tahmeed Ahmed (TA) and Mohammod Jobayer Chisti (MJC) with a PhD, they (both male) were Co-Principal Investigator of this study. They are working as a Senior Scientist of Nutrition and Clinical Services Division of icddr,b. Haribondhu Sarma (SM) with a PhD was an Investigator of this study. He (HS) is working at Australian National University, Acton, ACT 2601, Australia.

\section{Authors' contributions}

MFU prepared the first draft of the manuscript with the guidance of SM and HS. MFU, MAH, MAI and JJ were involved in data collection and analysis. SM, HS, KM, TA \& MJC contributed to the study design and critically reviewed the manuscript. MFU, under the mentorship of HS and SM was responsible for the overall development of the manuscript. All authors read, critically reviewed and approved the final draft of the manuscript.

\section{Funding}


This work was supported by the Bill and Melinda Gates Foundation awarded to the CHAIN Network (grant: OPP1131320), and in part by a Wellcome Trust \& MRC Newton Fund Collaborative Award (grant: 200344/Z/15/Z). The results and interpretation presented here do not necessarily reflect the views of the study funders.

\section{Availability of data and materials}

The date sets cannot be shared publicly due to institutional roles and regulations. Data generated during the study will be provided to interested researchers (Recipients) from the corresponding author on reasonable request.

\section{Ethics approval and consent to participate}

The study was approved by the Research Review Committee and the Ethical Review Committee of icddr,b (Study Protocol Number-PR-16056). Informed written consent was obtained from the participants before enrollment of the children into the study and conducting the interviews with participants.

\section{Consent for publication}

Permission to publish this paper was obtained from the Senior Division Director, Nutrition and Clinical Services Division, icddr,b, Dhaka, Bangladesh.

\section{Competing interests}

The authors declare that they have no competing interests

\section{Author details}

${ }^{1}$ Nutrition and Clinical Services Division, icddr,b, GPO Box 128, Dhaka 1000, Bangladesh

${ }^{2}$ KEMRI-Wellcome Trust Research Programme, P.O. Box 230-80108, Kilifi, Kenya

${ }^{3}$ Centre for Tropical Medicine and Global Health, University of Oxford, United Kingdom

${ }^{4}$ KEMRI-Wellcome Trust Research Programme, P.O. Box 43640-00100, Nairobi, Kenya

${ }^{5}$ Departments of Global Health, Medicine, Pediatrics and Epidemiology, University of Washington

${ }^{6}$ Research School of Population Health, Australian National University, Acton, ACT 2601, Australia.

\section{References}

1. Ngari MM, Fegan G, Mwangome MK, Ngama MJ, Mturi N, Scott JAG, et al. Mortality after inpatient treatment for severe pneumonia in children: a cohort study. Paediatric and Prenatal Epidemiology. 2017;31(3):233-42.

2. English L, Kumbakumba E, Larson CP, Kabakyenga J, Singer J, Kissoon N, et al. Pediatric out-of-hospital deaths following hospital discharge: a mixedmethods study. African Health Sciences. 2016;16(4):883-91.

3. Moisi JC, Gatakaa H, Berkley JA, Maitland K, Mturi N, Newton CR, et al. Excess child mortality after discharge from hospital in Kilifi, Kenya: a retrospective cohort analysis. Bulletin of the World Health Organization. 2011; 89(10): 725-32, 32A.

4. Chisti MJ, Graham SM, Duke T, Ahmed T, Faruque ASG, Ashraf H, et al. Post-discharge mortality in children with severe malnutrition and pneumonia in Bangladesh. PloS One. 2014; 9(9): e107663.

5. Wiens MO, Pawluk S, Kissoon N, Kumbakumba E, Ansermino JM, Singer J, et al. Pediatric post-discharge mortality in resource poor countries: a systematic review. PloS One. 2013;8(6):e66698.

6. Nemetchek B, English L, Kissoon N, Ansermino JM, Moschovis PP, Kabakyenga J, et al. Paediatric post-discharge mortality in developing countries: a systematic review. BMJ Open. 2018; 8(12), e023445

7. Black RE, Victora CG, Walker SP, Bhutta ZA, Christian P, De Onis M, et al. Maternal and child undernutrition and overweight in low-income and middleincome countries. Lancet. 2013;382:427-51.

8. Veirum JE, Sodeman M, Biai S, Hedegard K, Aaby P. Increased mortality in the year following discharge from a paediatric ward in Bissau, Guinea-Bissau. Acta Paediatrica. 2007;96: 1832-1838

9. Islam MA, Rahman MM, Mahalanabis D, Rahman AM. Death in a diarrhoeal cohort of infants and young children soon after discharge from hospital: risk factors and causes by verbal autopsy. Journal of Tropical1996;42(6):342-7.

10. Musinguzi G, Anthierens S, Nuwaha F, Van Geertruyden JP, Wanyenze RK, Bastiaens H. Factors Influencing Compliance and Health Seeking Behaviour for Hypertension in Mukono and Buikwe in Uganda: A Qualitative Study. International Journal of Hypertension. 2018; Article ID 8307591, 13 pages.

11. Gloyd S, Kone A, Victor AE. Pediatric discharge against medical advice in Bouake Cote d'Ivoire, 1980-1992. Health Policy Plan. 1995; $10: 89-93$.

12. Naila N, Nahar B, Lazarus M, Ritter G, Hossain M, Mahfuz M, et al. "Those who care much, understand much." Maternal perceptions of children's appetite: Perspectives from urban and rural caregivers of diverse parenting experience in Bangladesh. Matern Child Nutr. 2018 Jan;14(1).

13. Rahman A, Rahman M, Pervin J, Razzaque A, Aktar S, Ahmed JU, et al. Time trends and sociodemographic determinants of preterm births in pregnancy cohorts in Matlab, Bangladesh, 1990-2014. BMJ Glob Health. 2019 Aug 2;4(4). 
14. Rahman M, DaVanzo J, Razzaque A.Pregnancy Termination in Matlab, Bangladesh: Maternal Mortality Risks Associated with Menstrual Regulation and Abortion. Int Perspect Sex Reprod Health. 2014;40(3):108-18.

15. Levay AV, Mumtaz Z, Rashid SF, Willows NJRH. Influence of gender roles and rising food prices on poor, pregnant women's eating and food provisioning practices in Dhaka, Bangladesh. Reprod Health, 2013; Sep 26;10:53.

16. Zakayo SM, Njeru RW, Sanga G, Mary N. Kimani, Charo A, et al. Vulnerability and agency across treatment-seeking journeys for acutely ill children: how family members navigate complex healthcare before, during and after hospitalisation in a rural Kenyan setting. International Journal for Equity in Health. Int J Equity Health 19, 136 (2020). https://doi.org/10.1186/s12939-020-01252-x

17. Roy S, Chowdhury A, Rahaman M. Excess mortality among children discharged from hospital after treatment for diarrhoea in rural Bangladesh. Br Med $\mathrm{J}$ (Clin Res Ed). 1983; 287(6399): p. 1097-1099.

18. Ashraf H, Alam NH, Chisti MJ, Mahmud SR, Hossain MI, Ahmed T, et al. A Follow-up Experience of 6 months after Treatment of Children with Severe Acute Malnutrition in Dhaka, Bangladesh. Journal of Tropical Pediatrics. 2012;58(4):253-7.

19. Illness CA. The Childhood Acute Illness and Nutrition Network. Childhood Acute Illness and Nutrition (CHAIN) Network: a protocol for a multi-site prospective cohort study to identify modifiable risk factors for mortality among acutely ill children in Africa and Asia. BMJ Open. $2019 ; 9(5): e 028454$.

20. Tickell KD, Mangale DI, Tornberg-Belanger SN, Bourdon C, Thitiri J, Timbwa M, et al. A mixed method multi-country assessment of barriers to implementing pediatric inpatient care guidelines. PLoS One.2019;14(3): e0212395. https://doi.org/10.1371/journal.pone.0212395

21. The World Bank. Economic Reforms Can Make Bangladesh Grow Faster [Internet]. 2018. https://www.worldbank.org/en/news/pressrelease/2018/10/02/economic-reforms-can-make-bangladesh-grow-faster. Accessed 3 October, 2019.

22. Central Intelligence Agency. The World Factbook 2020. https://www.cia.gov/library/publications/the-world-factbook/geos/bg.html. Accessed 10 Januray, 2020.

23. World Health Organization. Bangladesh health system review. 2015. Vol. 5 No. 3. https://apps.who.int/iris/bitstream/handle/10665/208214/9789290617051_eng.pdf?sequence=1\&isAllowed=y. Accessed 10 June, 2020.

24. Islam R, Hossain S, Bashar F, Khan SM, Sikder AAS, Yusuf SS, et al. Contracting-out urban primary health care in Bangladesh: a qualitative exploration of implementation processes and experience. Int J Equity Health. 2018;17(1):93.

25. Mahfuz M, Alam MA, Islam SB, Naila NN, Chisti MJ, Alam NH, et al. Treatment outcome of children with persistent Diarrhoea admitted to an Urban Hospital, Dhaka during 2012-2013. BMC Pediatr. 2017;17(1):142.

26. Schwartz LM, Zaman K, Yunus M, Basunia A-uH, Faruque ASG, Ahmed T, et al. Impact of Rotavirus Vaccine Introduction in Children Less Than 2 Years of Age Presenting for Medical Care With Diarrhea in Rural Matlab, Bangladesh. Clin Infect Dis. 2019;69(12):2059-2070.

27. Das SK, Faruque ASG, Chisti MJ, Malek MA, Salam MA, Sack DA. Changing trend of persistent diarrhoea in young children over two decades: observations from a large diarrhoeal disease hospital in Bangladesh. Acta Paediatr. 2012;101:e452-7.

28. Huda FA, Ahmed A, Dasgupta SK, Jahan M, Ferdous J, Koblinsky M, et al. Profile of Maternal and Foetal Complications during Labour and Delivery among Women Giving Birth in Hospitals in Matlab and Chandpur, Bangladesh. J Health Popul Nutr. 2012;30(2):131.

29. Ahmed T, Ali M, Ullah M, Choudhury I, Haque E, Salam A, et al. Mortality in severely malnourished children with diarrhoea and use of a standardised management protocol. Lancet.1999;353:1919-22.

30. icddr b. Clinical facilities. 2020. https://www.icddrb.org/research/platforms/clinical-facilities. Accessed 23 December, 2019.

31. Fakir AM, Khan MW. Determinants of malnutrition among urban slum children in Bangladesh. Health Econ Rev. 2015, 5(1):59.

32. Ferdous F, Das SK, Ahmed S, Farzana FD, Malek MA, Das J, et al. Diarrhoea in slum children: observation from a large diarrhoeal disease hospital in Dhaka, Bangladesh. Trop Med Int Health. 2014; 19(10):1170-6.

33. Joshi S, Schultz TP. Family Planning and Women's and Children's Health: Long-Term Consequences of an Outreach Program in Matlab, Bangladesh. Demoghraphy. 2013; 50(1):149-80.

34. Nair NS, Lewis LE, Lakiang T, Godinho MA, Murthy S, Venkatesh BT. Risk factors and barriers to case management of neonatal pneumonia: protocol for a pan-India qualitative study of stakeholder perceptions. BMJ Open. 2017;7(9):e017403.

35. Uddin FM, Molyneux S, Muraya K, Hossain MA, Islam MA, Zakayo SM, et al. Our son is 'our asset, future, and bank': exploring gender-related influences on post-hospital discharge adherence to advice and treatment-seeking for infants and young children in Bangladesh.2020. (Unpublished)

36. George A, Colleagues. Structural determinants of gender inequality: why they matter for adolescent girls' sexual and reproductive health. BMJ. 2020;368:16985. doi: 10.1136/bmj.16985

37. Mondal P, Islam MM, Hossain M, Huq S, Shahunja K, Alam M, et al.Post-discharge morbidities and mortalities among children with severe acute malnutrition who did not undergo nutrition rehabilitation. Adv Pediatr Res. 2017; 4:15. doi:10.12715/apr.2017.4.1

38. Ranganathan $\mathrm{M}$, Lagarde M. Promoting healthy behaviours and improving health outcomes in low and middle income countries: A review of the impact of conditional cash transfer programmes. Preventive Medicine. 2012; 55: S95-S105.

39. Moncayo AL, Granizo G, Grijalva MJ, Rasella D. Strong effect of Ecuador's conditional cash transfer program on childhood mortality from poverty-related diseases: a nationwide analysis. BMC Public Health. 2019;17;19(1):1132.

40. Mercer A, Haseen F, Huq NL, Uddin N, Hossain Khan M, Larson CP. Risk factors for neonatal mortality in rural areas of Bangladesh served by a large NGO programme. Health Policy Plan. 2006; 21: 432-443.

41. D'Souza RM. Role of health-seeking behaviour in child mortality in the slums of Karachi, Pakistan. J Biosoc Sci. 2003; 35: 131-144. 
42. Zurovac D, Sudoi RK, Akhwale WS, Ndiritu M, Hamer DH, Rowe AK, et al.The effect of mobile phone text-message reminders on Kenyan health workers' adherence to malaria treatment guidelines: a cluster randomised trial. Lancet. 2011; 378: 795-803.

43. Palmer MJ, Barnard S, Perel P, Free C. Mobile phone-based interventions for improving adherence to medication prescribed for the primary prevention of cardiovascular disease in adults. Cochrane Database Syst Rev. 2018 Jun 22;6(6):CD012675.

44. Yasmin F, Banu B, Zakir SM, Sauerborn R, Ali L, Souares A. Positive influence of short message service and voice call interventions on adherence and health outcomes in case of chronic disease care: a systematic review. BMC Med Inform Decis Mak. 2016 Apr 22;16:46. doi: 10.1186/s12911-016-0286-3.

45. Khatun F, Hanifi S, Iqbal M, Rasheed S, Rahman MS, Ahmed T, et al.Prospects of mHealth Services in Bangladesh: Recent Evidence from Chakaria. PLoS ONE. 2014; 9(11): e111413. doi:10.1371/journal.pone.0111413.

46. Huda TM, Alam A, Tahsina T, Hasan MM, Khan J, Rahman MM, et al. Mobile-Based Nutrition Counseling and Unconditional Cash Transfers for Improving Maternal and Child Nutrition in Bangladesh: Pilot Study. JMIR Mhealth Uhealth. 2018;6(7):e156.

47. Isturiz RE, Carbon C: Antibiotic use in developing countries. Infect Control Hosp Epidem. 2000; 21(6):394-397.

48. Llor C, Bjerrum L. Antimicrobial resistance: risk associated with antibiotic overuse and initiatives to reduce the problem. Therapeutic Advanves in Drug Safety, 2014;5(6):229-41.Ther Adv Drug Saf. 2014;5(6):229-41. doi: 10.1177/2042098614554919.

49. Systems for Improved Access to Pharmaceuticals and Services (SIAPS). Baseline study of private drug shops in Bangladesh: findings and recommendations. 2015. http:// siapsprogram. org/ publication/altview/ baseline- study- of- private- drug- shops- in- bangladeshfindings- andrecommendations/ english/. Accessed 25 Nov 2019.

50. Ahmed SM, Islam QS. Availability and rational use of drugs in primary healthcare facilities following the national drug policy of 1982 : is Bangladesh on right track? J Health Popul Nutr. 2012;30:99-108.

51. Dillip A, Embrey M, Shekalaghe E, Ross-Degnan D, Vialle-Valentin C, Kimatta S, et al.What motivates antibiotic dispensing in accredited drug dispensing outlets in Tanzania? A qualitative study. Antimicrob Resist Infect Control. 2015; 4(1):30.

52. Mohiuddin M, Rashid SF, Shuvro MI, Nahar N, Ahmed SM. Qualitative insights into promotion of pharmaceutical products in Bangladesh: how ethical are the practices? BMC Med Ethics. 2015;16(1):80. doi: 10.1186/s12910-015-0075-z.

\section{Figures}

\begin{tabular}{|l|}
\hline $\begin{array}{l}\text { Socio-cultural and } \\
\text { environmental factors } \\
\text { - } \\
\text { Tradition/law/customs } \\
\text { Gender and other } \\
\text { social relations } \\
\text { Household } \\
\text { environment } \\
\text { Childcare practices }\end{array}$ \\
\hline
\end{tabular}

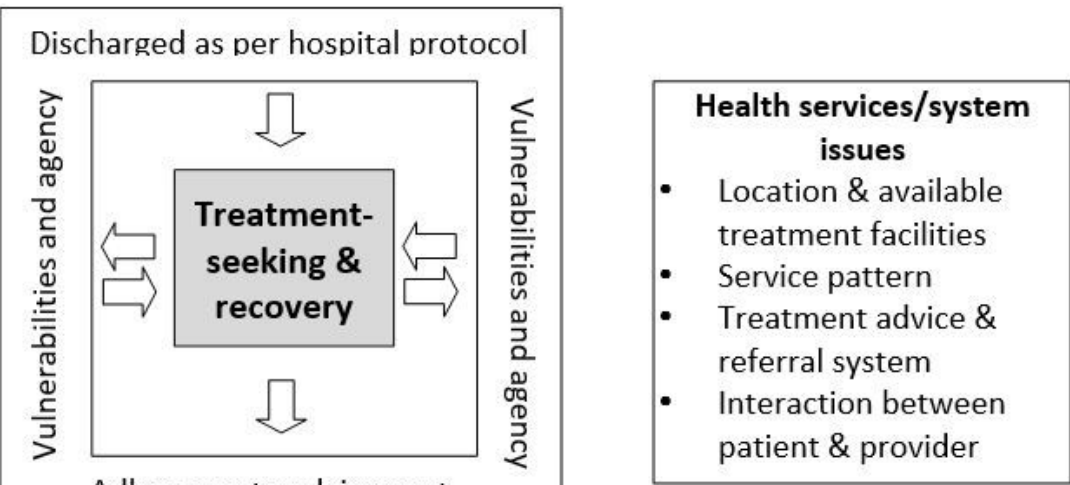

\begin{tabular}{|l|}
\multicolumn{1}{c|}{ Affordability of health care } \\
- \\
-
\end{tabular}

Figure 1

Conceptual framework for understanding the factors influencing the post-hospital discharge treatment-seeking and recovery

\section{Supplementary Files}

This is a list of supplementary files associated with this preprint. Click to download.

- Additionalfile2COREQChecklist.docx

- Additionalfile1 InterviewGuide.docx 